\title{
Clinical, Pathological, and Hematological Study of Post-Injection Neuritis of the Sciatic Nerve by Alfatrim 24\% Intramuscular Injection in Small Ruminants
}

Farhang Sasani ${ }^{1 *}$, Javad Javanbakht ${ }^{1}$, Feridon Nourmohammadzadeh ${ }^{2}$, Mehdi Aghamohammad Hassan², Mehdi Rajabi Moghaddam ${ }^{3}$ and Aniseh Talebi ${ }^{3}$

${ }^{1}$ Department of Pathology, Faculty of Veterinary Medicine, University of Tehran, Tehran, Iran

${ }^{2}$ Department of Clinical Science, Faculty of Veterinary Medicine, University of Tehran, Tehran, Iran

${ }^{3}$ Faculty of Veterinary Medicine, University of Tehran, Tehran, Iran

\begin{abstract}
Medication therapy through improper injection techniques into a nerve may induce neuropathy, neuritis \& injury. The aim is to analyse the pattern of this nerve lesion in clinical, pathological, and hematological parameters and also to study the outcome in a conservatively treated cohort. In this study, 40 cases of sheeps and goats about 3 years old, had received Alfatrim 24\%, $1 \mathrm{cc}$ per $20 \mathrm{~kg} \mathrm{BW}$ in the rout of intramuscular each 12 hours for 3 days. The clinical signs included loss of function in nearly all of the hind limbs, with loss of skin sensation from the lateral surface of the tibial region of the hock joint to the distal parts. The foot is dragged in a manner of pulling his leg upward and forward in each gait by contraction of the quadriceps muscles which are innervated by the femoral nerve. In hematological examination, mature neutrophils of white and black goats were $73 \%$ and $61 \%$ respectively. However, normal value of mature neutrophils is $10-59 \%$ in goats. In addition, glucose and total protein were respectively $59 \mathrm{mg} / \mathrm{dl}$ and $1 \mathrm{~g} / \mathrm{dl}$ in white goat's CSF, whereas normal value of glucose and total protein in CSF are $71 \mathrm{mg} / \mathrm{dl}$ and $0.12-0.25 \mathrm{~g} / \mathrm{dl}$ respectively. Furthermore, a sort of lameness took place by neuronal origin bilaterally following Alfatrim $24 \%$ injection intramuscularly, permanent occasionally, was a common consequence for intramuscular injection. Macroscopic lesions were swelling of sciatic nerve stem, submeningeal hemorrhage, fibrinopurulent inflammation \& necrosis. In microscopic lesions neuronal fibers were normal (axon \& myelin sheath), but there were fibrinous lymphoplasmacytic perineuritis, subepineuronal hemorrhage. Some of cases showed recovery 4 days after receiving Ibuprofen. Further studies on the effects of Alfatrim $24 \%$ on sciatic nerve in small ruminants need to be conducted. In particular, experimental studies will assist in the understanding of Alfatrim $24 \%$ and its relation to sciatic neuritis in small ruminants.
\end{abstract}

Keywords: Sciatic nerve; Alfatrim; Hematological; Pathological; Small ruminant

\section{Introduction}

Damage to the sciatic nerve by injection has been reported from several parts of the world; these injuries are related mainly to a faulty injection technique and lack of trained man power capable of administering paranteral drugs in the developing countries [1-3]. Injection injury account for $50 \%$ of sciatic nerve injuries in one large series reported from the USA [4].

Sciatic nerve injury and dysfunction is not an uncommon cause of lower extremity symptoms in a musculoskeletal practice. The sciatic nerve derives its nerve fibers from the $\mathrm{L} 4, \mathrm{~L} 5, \mathrm{~S} 1, \mathrm{~S} 2$, and $\mathrm{S} 3$ nerve roots. The sciatic nerve arises from the lumbosacral plexus and is composed of two distinct trunks: the lateral (peroneal division) and the medial (tibial division). The peroneal and the tibial divisions lie next to each other to form the sciatic nerve. The divisions physically separate from each other at the midthigh to the distal thigh to form the common peroneal and tibial nerves. Occasionally, the divisions separate at the proximal thigh [5].

Sciatic neuropathy can be the result of any focal lesion of the nerve in the hip or thigh, distal to the lumbosacral plexus but proximal to the separation of the nerve into its distal branches. The lesion can involve demyelinative injury, axonal injury, mixed axonal and demyelinative injury, or partial or complete nerve discontinuity [6].

Etiologies of sciatic neuropathy can include traumatic, compressive, ischemic, neoplastic, or idiopathic etiologies. Traumatic injuries can include injury to the sciatic nerve in association with femur fracture, hip dislocation or fracture, laceration, gunshot wound, or posterior thigh compartment syndrome [5,7-10]. Compressive injuries can include compression from compartment syndrome, hematoma, hamstring injuries, fibrous bands, persistent sciatic artery, or controversially, from piriformis syndrome [5,11-13]. Temporary lameness in goats is common following injections by irritant substances such as Tetracycline and Enrofloxacin due to relatively small musculature in the hind limb, especially in gluteal region. A type of more permanent lameness may result from damage to the sciatic or peroneal nerves [11].

Medication therapy through improper injection techniques into a nerve may induce neuropathy, neuritis \& injury. Iatrogenic nerve damage by injections may originate from needle puncture, the medication deposition, pressure from a hematoma or scarring around the nerve. The various combinations may contribute to injury. In domestic animals, the sciatic nerve is the most commonly damaged by deep intramascular injections [14-16].

*Corresponding author: Farhang Sasani, Faculty of Veterinary Medicine Department of Pathology, University of Tehran, Tehran, Iran, Tel:+989121573490 E-mail: fsasani@ut.ac.ir

Received October 06, 2013; Accepted November 13, 2013; Published November 18, 2013

Citation: Sasani F, Javanbakht J, Nourmohammadzadeh F, Hassan AM Moghaddam MR, et al. (2013) Clinical, Pathological, and Hematological Study of Post-Injection Neuritis of the Sciatic Nerve by Alfatrim 24\% Intramuscular Injection in Small Ruminants. Brain Disord Ther 2:111. doi:10.4172/2168-975X.1000111

Copyright: @ 2013 Sasani F, et al. This is an open-access article distributed under the terms of the Creative Commons Attribution License, which permits unrestricted use, distribution, and reproduction in any medium, provided the original author and source are credited. 
Citation: Sasani F, Javanbakht J, Nourmohammadzadeh F, Hassan AM, Moghaddam MR, et al. (2013) Clinical, Pathological, and Hematological Study of Post-Injection Neuritis of the Sciatic Nerve by Alfatrim 24\% Intramuscular Injection in Small Ruminants. Brain Disord Ther 2:111. doi:10.4172/2168-975X.1000111

In the Alfasan international BV $11 / 99$ of Alfatrim 24\% (drug brochure) is indicated that adverse reactions of Alfatrim 24\% are as polyarthritis, urticaria, facial swelling, fever, hemolytic anemia, polydipsia, polyuria, vomiting, anorexia, diarrhea \& seizure. In some animals, it may result from localized and generalized hypersensitivity and sometimes fatal reactions. In the site of injection the pain, swelling, secondary inflammation \& necrosis were visible. It is also possible that high dose administration at one site may cause symptoms of intolerance. Administration to very young adults is not recommended [brochure]. According to brochure of Alfatrim 24\%, each $\mathrm{ml}$ of this solution contains $40 \mathrm{mg}$ Trimethoprim and $200 \mathrm{mg}$ Sulfamethoxazole. Sulfonamides block dihydrofolic acid Synthesis by competing with Para Aminobenzoic Acid (PABA) for binding sites on dihydropteroate synthetase. Dihydrofolic acid is necessary for the synthesis of tetrahydrofolic acid (DNA); hence the bacterial growth is inhibited without this substance [1]. Trimethoprim potentiates the antimicrobial activity synergistic effects [3]. Antimicrobial efficiency can be obtained on very low levels of the drug combinations [2].

The study was conducted to analyse the pattern of this nerve lesion in clinical, pathological, and hematological parameters and also to study the outcome in a conservatively treated cohort.

\section{Materials and Methods}

In present research, 40 cases of goats about 3 years old, were administered Alfatrim 24\% $1 \mathrm{cc}$ per $20 \mathrm{~kg}$ BW through intramuscular route injection in femoral \& gluteal muscles, each 12 hours for 3 days. Subsequently, tissue specimens were fixed in $10 \%$ of neutral buffered formalin, embedded in paraffin and sectioned at 5 micron pieces by microtome LElCA RM 2135 model. The prepared sections were stained by H\&E method.

\section{Results}

After a 10-day period, 8 cases indicated weakness, lameness, ataxia and solely one case developed tachycardia (140/min) and tachypnea $(48 / \mathrm{min})$. It is noticeable that clinical signs were recorded 5 minutes after injection.

Clinical signs included lameness, loss of function in the hind limbs with loss of skin sensation on the lateral surface on the tibial region, hock \& elbow. The feet were dragged with each step. In some of cases after 5 minutes, clinical findings were appeared.In some cases clinical findings were appeared after 5 minutes (Figures 1 and 2).

In hematological examination the rate of mature neutrophils was $61-73 \%$, and the level of Glucose and total protein in CSF was $59 \mathrm{mg} / \mathrm{dl}$ and $1 \mathrm{gr} / \mathrm{dl}$ respectively (Table 1 ).

Macroscopic lesions were as swelling of sciatic nerve system, submeningeal hemorrhage. Microscopically, neuronal fibers were normal (axon \& myelin sheath); however, the fibrinopurulent inflammation \& necrosis, fibrinous lymphoplasmacytic perineuritis and subepineuronal hemorrhage were detected. Some of cases showed recovery 4 days following receiving Ibuprofen (Figures 3-5).

\section{Discussion}

Sciatic neuropathy is second commonest mononeuropathy in the lower limb after common peroneal nerve injury. The combination of trimethoprim and sulfamethoxazole secures a synergistic action against majority of gram positive and gram negative bacteria including penicillinase producing ones. In addition, some streptococcal strains are only moderately sensitive such as Brucella, Erysiplothrix, Nocardia

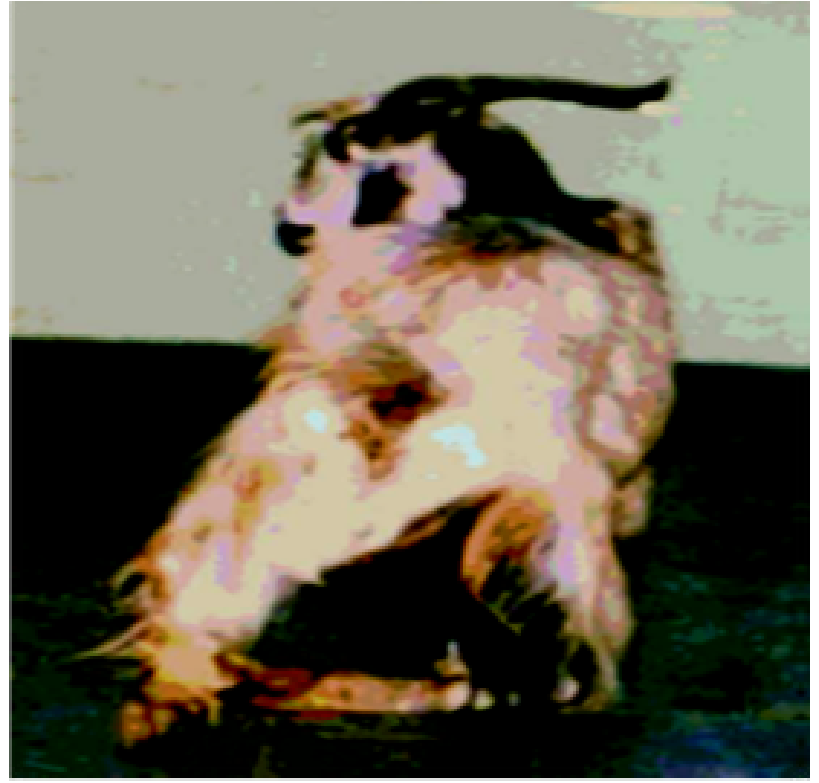

Figure 1: Goat: Kneeled down and fell on knees

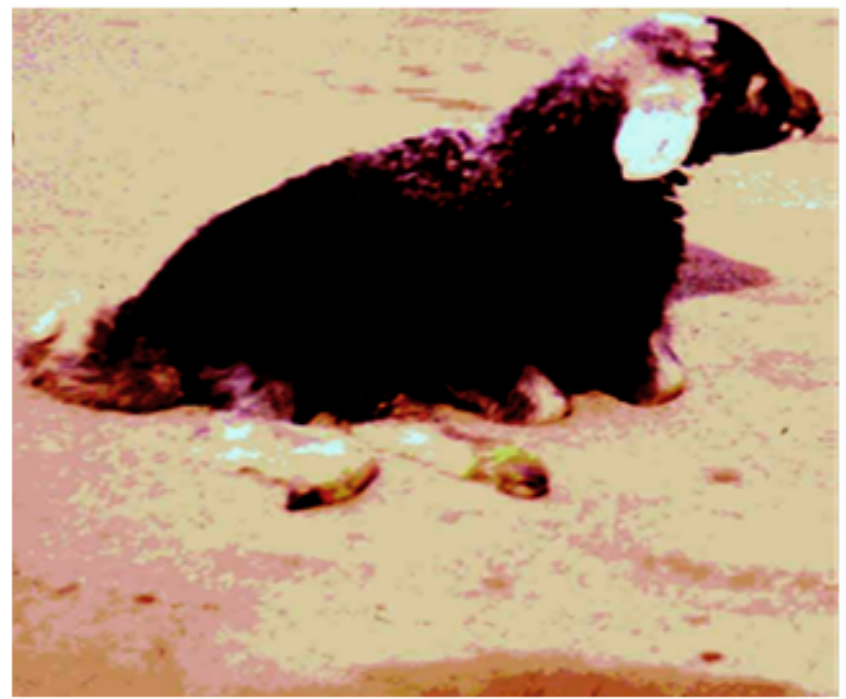

Figure 2: Lamb: Recumbence, lameness, and ataxia

\begin{tabular}{|l|l|l|}
\hline Parameter & Group I & Group II \\
\hline PCV $(\%)$ & 29 & 25 \\
\hline WBC $(\times 109 / \mathrm{L}$ & 11000 & 2500 \\
\hline Neutrophil $(\%)$ & 73 & 61 \\
\hline Lymphocyte $(\%)$ & 25 & 36 \\
\hline Basophil $(\%)$ & 2 & 3 \\
\hline Total protein $(\mathrm{gr} / \mathrm{l})$ & 7.8 & 6.9 \\
\hline Fibrinogen $(\mathrm{mg} / \mathrm{dl})$ & 700 & 400 \\
\hline
\end{tabular}

Table 1 : Some Hematological and Biochemical parameters in two cases of goats

and Moraxella, whereas Leptospira, Pseudomonas and Mycobacterium are not very sensitive $[6,7,17,18]$.

These two components effect on the synthesis of bacterial purine and nucleic acids in a different way, resulting in a double blockade. Furthermore, Alfatrim $24 \%$ can be used in primary and secondary bacterial diseases such as Respiratory, GI tract, Genital and urinary 
Citation: Sasani F, Javanbakht J, Nourmohammadzadeh F, Hassan AM, Moghaddam MR, et al. (2013) Clinical, Pathological, and Hematological Study of Post-Injection Neuritis of the Sciatic Nerve by Alfatrim 24\% Intramuscular Injection in Small Ruminants. Brain Disord Ther 2:111. doi:10.4172/2168-975X.1000111

Page 3 of 4

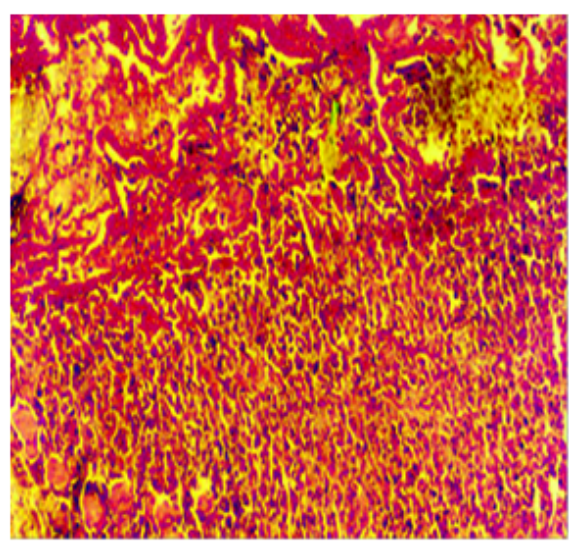

Figure 3: Zenker's necrosis, collagen degeneration, lymphoplasmacytic and neutrophilic myositis. H\&E $(\times 40)$

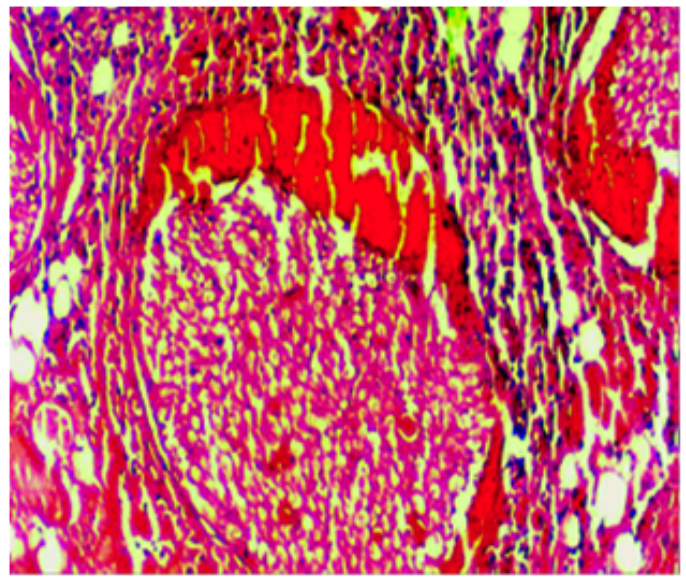

Figure 4: Subperineural hemorrhage and perineural and interstitial lymphoplasmacytic infiltration. H\&E $(\times \mid 00)$

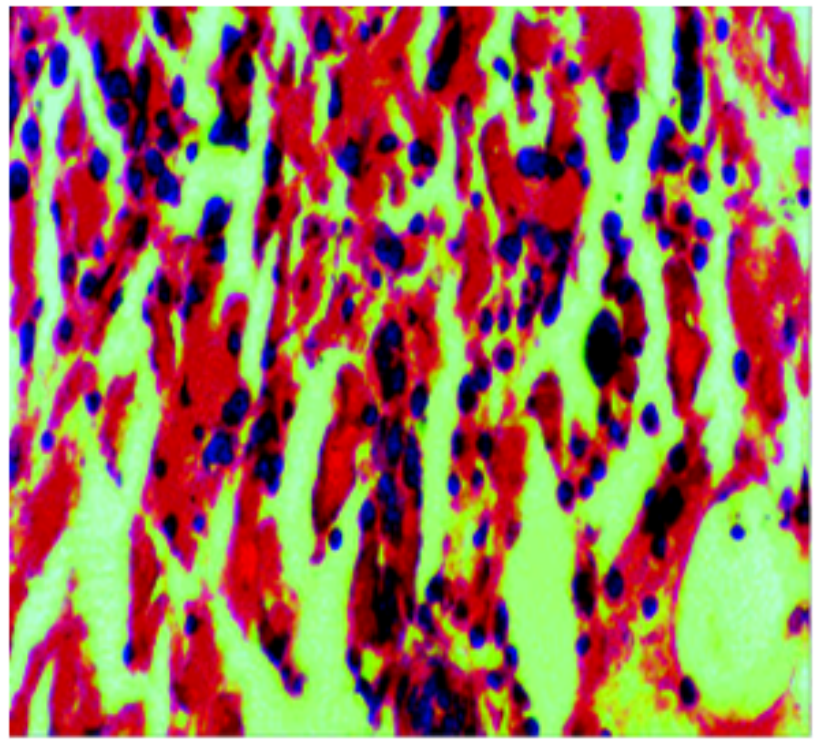

Figure 5: Lymphoplasmacytic perineuritis and edema. H\&E (×400) infections, mastitis, wound infections, eye and ear infections in cattle, calves, pigs, dogs and cats. Thus, trauma is the usual cause of peripheral injuries, leading to paralysis. Although injury may occur to all of the peripheral nerves, the most common peripheral nerve dysfunction in goats is damage to the sciatic nerve, originating from mechanical injury by poor intramuscular injection techniques or the introduction of irritating medications on or near the nerve. The sciatic nerve and its terminal branches as tibial and proneal nerves are the most commonly injured peripheral nerves of hind limbs $[6,17,19]$.

In present report, adjuvant or drug might be the cause of producing such kinds of lesion [18,20]. Side effects due to the potentiated sulfonamides are absolutely scarcely, although adverse reactions to the sulfonamides components still occur. The recommended dose of trimethoprim has been administered up to 10 times without adverse outcomes [7].

Additionally, infiltration of lymphocytes and plasmacytes may be the result of immunologic reaction and purulent myositis may be sign of the secondary bacterial infection. Overall, the severity of the damage varies with the type and dose of medication. On the other hand, specific drugs and toxic chemicals like toxic levels of organophosphates have greater potential for axonal damage induction $[4,18,21]$. Hence, precise care should be taken after intramuscular injections, as permanent lameness may occur since the goats have fairly small muscle masses in their hind limbs, which are particularly in the gluteal region.

The volume of the drug administered at one side hardly should be more than $5 \mathrm{ml}$, using a needle of 18 (gauge) or less and 25-38 mm (11.5 inches) in length for adult goats. Therefore, smaller amounts and shorter needles are efficient in kids. Finally, It is always safer to use the subcutaneous route than intramuscular injections, so this route should be adapted wherever possible [11,22-24]. In a study, this compound (by IM, IV \& SC) was injected into 2300 sheep \& goats, and triggered locomotion problems in 310 cases clinical signs included lameness, loss of function in the hind limbs with loss of skin sensation on the lateral surface on the tibial region, hock \& elbow. The feet were dragged in each gait.

\section{Conclusion}

In conclusions, further studies on the effects of Alfatrim $24 \%$ on sciatic nerve in small ruminants need to be conducted .In particular, experimental studies will assist in the understanding of Alfatrim 24\% and its relation to sciatic neuritis in small ruminants.

\section{Acknowledgments}

The authors thank staff of the Veterinary Teaching Hospital, Tehran University for their valuable technical assistance. We appreciate important individuals who have helped us in carrying out such work.

\section{References}

1. Ahrens FA (1996) The National Veterinary Medical Series, Pharmacology. Williams \& Wilkins

2. Blood DC, Radostits OM (1989) Veterinary Medicine. (7thedn), Bailliere Tindall.

3. Busby SRM (1980) Sulfonamide and trimethoprim combinations. Journal of American Veterinary Medicine Association 176: 1049-1053.

4. Dunlop $\mathrm{RH}$, Malbert $\mathrm{CH}$ (2004) Veterinary Pathophysiology, Ames.IA Blackwell Oxford UK

5. Fishman LM, Schaefer MP (2003) The piriformis syndrome is underdiagnosed Muscle Nerve 28: 646-649.

6. Howard J L, Smith RA (2000) Current Veterinary Therapy 4. Food Animal Practice. (4thedn), Sounders. 
Citation: Sasani F, Javanbakht J, Nourmohammadzadeh F, Hassan AM, Moghaddam MR, et al. (2013) Clinical, Pathological, and Hematological Study of Post-Injection Neuritis of the Sciatic Nerve by Alfatrim 24\% Intramuscular Injection in Small Ruminants. Brain Disord Ther 2:111. doi:10.4172/2168-975X.1000111

Page 4 of 4

7. Kahn CM (2005) The Merc Veterinary Manual. (9thedn), Merc \& co, INC.

8. Kim DH, Murovic JA (2004) Management and outcomes in 353 surgically treated sciatic nerve lesions. J Neurosurg 101: 8-17.

9. Kline D G, Kim D, Midha R, Harsh C, Tiel R (1998) Management and results of sciatic nerve injuries: A 24-years experience. J Neurosurgery 89: 13-23.

10. Kotwal A, Priya R, Thakur R, Gupta V, Kotwal J, et al. (2004) Injection Practices in Metropolis of North India: perceptions, determinants and issues of safety. Indian J Med Sci 58: 334-344.

11. Matthews J (1999) Disease of goats. (2ndedn), Blackwell science.

12. Plewnia $C$, Wallace $C$ (1999) Traumatic sciatic neuropathy: à novel cause, local experience and a review of the literature. J Trauma 47: 986-999.

13. Puranen J, Orava S (1988) The hamstring syndrome. A new diagnosis of gluteal sciatic pain. Am J Sports Med 16: 517-521.

14. Raglow GJ, Luby SP, Nabi N (2001) Therapeutic injection in Pakistan from the patients perspective. Trop Med Int Health 6: 69-75.

15. Schmalzried TP, Eckardt JJ (1992) Spontaneous gluteal artery rupture resulting in compartment syndrome and sciatic neuropathy. Report of a case in EhlersDanlos syndrome. Clin Orthop Relat Res 27: 253-257.

16. Simonsen L, Kane A, Lioyd J, Zaffran M, Kane M (1999) Unsafe injection in the developing world and transmission of blood borne pathogens. Bull World Health Organ 77: 789-800.
17. Smith MC, Sheman DM (1994) Goat Medicine. (3rdedn), LEA \& FEBIGER.

18. Summers BA, Cummings JF, De Lahunta A (1995) Veterinary Neuropathology; Mosby-year book, Inc.

19. Sunderland S (1951) A classification of peripheral nerve injuries producing loss of function. Brain 74: 491-516.

20. Stewart JD (2003) The piriformis syndrome is overdiagnosed. Muscle Nerve 28: $644-646$

21. Tomaino MM (2002) Complete sciatic nerve palsy after open femur fracture: successful treatment with neurolysis 6 months after injury. Am J Orthop 31 : 585-588.

22. Yuen EC, So YT (1999) Entrapment and other focal neuropathies. sciatic neuropathy. Neurol Clin 17: 617-631.

23. Hobbenaghi R, Javanbakht J, Hosseini E, Mohammadi S, Rajabian M, et al (2013) Neuropathological and neuroprotective features of vitamin B12 on the dorsal spinal ganglion of rats after the experimental crush of sciatic nerve: an experimental study. Diagn Pathol 8: 123.

24. Javanbakht J, Hobbenaghi R, Hosseini E, Bahrami AM, Khadivar F, et al (2013) Histopathological investigation of neuroprotective effects of Nigella sativa on motor neurons anterior horn spinal cord after sciatic nerve crush in rats. Pathol Biol (Paris). 